\title{
Chinese Confucian culture and the medical ethical tradition
}

\author{
Guo Zhaojiang The Fourth Military Medical University, Xian, Shaanxi, China
}

\section{Abstract}

The Confucian culture, rich in its contents and great in its significance, exerted on the thinking, culture and political life of ancient China immense influences, unparalleled by any other school of thought or culture. Confucian theories on morality and ethics, with 'goodness' as the core and 'rites' as the norm, served as the 'key notes' of the traditional medical ethics of

China. The viewpoints of Confucianism on benevolence and material interests, on good and evil, on kindheartedness, and on character cultivation were all inherited by the medical workers and thus became prominent in Chinese traditional medical ethics. Hence, it is clear that the medical profession and Confucianism have long shared common goals in terms of ethics.

Influenced by the excellent Confucian thinking and culture, a rather highly-developed system of Chinese traditional medical ethics emerged with a well-defined basic content, and the system has been followed and amended by medical professionals of all generations throughout Chinese history. This system, just to mention briefly, contains concepts such as the need: to attach great importance to the value of life; to do one's best to rescue the dying and to heal the wounded; to show concern to those who suffer from diseases; to practise medicine with honesty; to study medical skills painstakingly; to oppose a careless style of work; to comport oneself in a dignified manner; to respect local customs and to be polite; to treat patients, noble or humble, equally, and to respect the academic achievements of others, etc.

Of course, at the same time, Confucian culture has its own historical and class limitations, which exerted negative influences on traditional medical ethics.

Now, if we are to keep up with the development of modern medicine, a serious topic must be addressed. That is how to retain the essence of our traditional medical ethics so as to maintain historic continuity and $y e t$, at the same time, add on the new contents of medical ethics so as to incorporate modern features into

\section{Key words}

Confucian ethical tradition; Chinese traditional medicine; modern medicine. our system. Therefore, when trying to reform medical practice in China, we are faced with the urgent need to inherit and promulgate the essence of Confucian ethics discarding its obsolete concepts - while at the same time building up the new medical ethics that can meet the requirements of the outside world and the future.

As the world strides into the twenty-first century, scholars around the world are contemplating, forecasting and portraying what the future will be like. In the next century, what kind of a world will we live in? How will we work? What moral values shall we need so as to co-ordinate and handle interpersonal rela- 8 tions and man's relation to society? These questions have provided much food for thought. One of the most heated debates centres on medicine, which is a common cause for all mankind, and medical ethics, which concerns each and every one of us. My topic for discussion is Chinese Confucian culture and the medical ethical tradition. I will expound on Chinese Confucian culture and its profound influences on, and the intrinsic connection with, the medical ethical tradition in China. I will also talk about the need for re-examining the moral values and ethical standards as embodied in Confucianism in order to meet the rapid developments in modern medicine.

\section{Confucian culture and its profound influences}

In the Spring and Autumn Period (770-476 BC), the slavery society in China was disintegrating and a new culture was being conceived which would shape future society. In this extraordinary period of history was born an extraordinary cultural giant, Kung Chiu, respectfully addressed by later generations as Kung Fu-tse or Confucius. Confucius (551-479 BC) was a distinguished philosopher, thinker, educator and political ethicist in the late Spring and Autumn Period (1). Although he was of humble origin, he had an acquisitive mind and a contemplative nature even as a child. $\mathrm{He}$ was once a petty official responsible for running a warehouse and raising cattle. Then he began to recruit disciples and to give lectures. He was the first to found a private 
school in China. Though he later held various highranking official positions in the state of $\mathrm{Lu}$, he was mainly interested in founding schools, giving lectures and promulgating and promoting his academic views and political ambitions. Together with his disciples he journeyed through much of the then politically and economically developed regions of China. The journey, which lasted fourteen years, helped him gain a deeper understanding of the then prevalent academic viewpoints and political beliefs of various schools as well as of social reality, through cultural exchange and observation. A unique school of Confucianism, which exerted immense influences on the thinking, culture and political life of ancient China, was established by Confucius as he made his profound inquiries into philosophical, ethical, political and educational problems.

\section{Concept of 'conscience'}

After the death of Confucius, his disciples inherited and developed his academic thoughts. Mencius (circa 390-305 BC), leader of one of the eight minor schools of thought developed from Confucianism, politically advocated the kingly way and opposed the way of might, and placed moral value on righteousness and despised profits. He was the first to formulate the concept of 'conscience' in the history of Chinese ethics and he was regarded by later generations as the true inheritor of Confucianism. Tsun-tse (circa 313-238 BC) criticized all other contending schools of thought and only revered Confucianism. Ethically, he concretized the concept of 'morality' and raised the possibility that 'man is born evil' as opposed to the hypothesis of Mencius that 'man is born good' (2).

In $213 \mathrm{BC}$, a well-known event in China's history took place. Emperor Qin Shihuang, who was offended by the political viewpoints of Confucian scholars, ordered the burning of classical writings of Confucianists and the killing of over 460 Confucian scholars. The tragedy dealt a heavy blow to the school of Confucianism and arrested its development for some time.

In the Han Dynasty (206 BC-220 AD), the importance of the school of Confucianism's tendency to support those in authority, such as monarchs, was recognised; Confucianism was for the first time crowned as the national orthodox culture when Emperor Han Wudi issued the decree 'to ban all other schools of thought and to sanctify Confucianism'. Confucian scholars in the period, as represented by Dong Zhongsu, adapted Confucianism to form philosophical theory about rulers. This promulgated the concept of 'the unity of heaven and man' and supported absolute monarchy (3).

During the Tang Dynasty (618-907) we saw the emergence of Taoism and Buddhism as rivals to Confucianism. Confucianism further developed in the process of both rejecting and absorbing Taoism and Buddhism. Han $\mathrm{Yu}$ et al tried to adapt $\frac{c}{\infty}$ Confucianism into a religious belief but failed (3) while other scholars developed the early Confucian $F$. thinking of 'valuing people and loving people'. In the interim, Confucianism was beginning to be merged with natural sciences and medicine.

In the Song $(960-1279)$ and the Ming (1368-1644) dynasties, Confucianism appeared in the form of 'Confucian idealist philosophy' out of $\frac{\overline{\bar{c}}}{\bar{\sigma}}$. the fusion of Confucianism with Taoism and $\stackrel{\Phi}{\complement}$ Buddhism, which later became the dominant philosophy of rulers in late feudal society $(960-1840)$ in $\overrightarrow{ }$

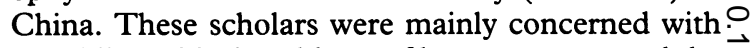
the philosophical problems of human nature and the $\vec{\omega}$ way of heaven and propounded the extreme proposi- $\stackrel{S}{?}$

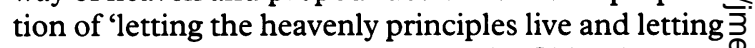
human desire perish'. Feudal rule in China became i more oppressive spiritually. These scholars alsomade great efforts to annotate classical Confucian $\dot{\sim}$ writings and consolidated the concept of 'national $\omega_{0}^{\omega}$ character' and the Confucian ideal of a prosperouso state and a humanitarian world. No noticeable $\rightarrow$ development in Confucianism occurred after the $\square$ Ming Dynasty.

Confucian culture by this time was extensive and $\stackrel{\text { क }}{\longrightarrow}$ wide-ranging, embracing the social, political, cultural, $\vec{\oplus}$ educational, ethical and moral aspects of life.

According to Confucian thinking, the ruling class should learn the merits and virtues of Yao and Tsum, who were legendary monarchs since time immerif orial in China (22nd-21st centuries, BC) and imitate Emperors Zhou Wenwang and Zhou足 Wuwang (circa 11 th century BC), two outstanding $\cong$ emperors of the Zhou Dynasty, in the way of govern- $\overrightarrow{\overrightarrow{0}}$ ing the state. Confucianists endorsed 'ritual' and 3 'goodness and justice' and advocated 'ruling by moral force' and 'ruling by ritual'. Confucius said:? 'If you rule the people and keep order among them by punishments ... they may avoid doing what is wrong, but they will also lose self respect. If you 3 . guide the people by moral force and keep order among them by ritual, they will keep their self $\frac{O}{3}$ respect and come to you of their own accord' (4). Mencius inherited Confucius's concept of benevo-J lent government and promoted the kingly way of ruling people by goodness and opposed ruling people through might.

\section{Profound implications}

Confucian culture is not just one academic school of thought, it has, profound connotations and implica- $-\frac{C}{-}$ tions. What is more important is that Confucius? inaugurated philosophical study in China and it can be said that he is the first great philosopher in China's history. He started academic debates of a philo- $\mathbb{\Phi}_{\vec{Q}}$ sophical nature on man's destiny versus human $\frac{\text { ?े }}{\mathbb{D}}$ efforts; on rule by benevolence versus rule by law; on the innate goodness or evil of human nature; on the process of knowledge acquisition; on methods of 
self-cultivation, and on other contentious topics. Confucianism is basically idealistic in nature, though among distinguished Confucian scholars of various dynasties one can always find some who were materialistic.

It is believed by Confucian scholars that education, especially moral education, plays a decisive role in ruling and keeping the state healthy, and that men can become knowledgeable, sensible and capable through education. Not surprisingly, Confucius started a private school with over 3,000 disciples. Some Confucian education theories about methods of study and scholarly research remain useful to later generations.

\section{Social order}

In Confucian culture, the importance of social ethics and morality is also highly emphasized and instruction in ethics and morality is integrated with politics. Thus, a special and unique unity of politics and ethics has formed. It is held that political rule should be supported by instruction in ethics and that each and every principle and norm of ethical instruction should be adapted so as to meet political needs. Therefore, Confucianism has become a school of thought which teaches rulers how to rule and the common people how to abide by that rule and behave properly - the aim being to maintain the social order which was based on hierarchy.

The essence of Confucian culture, either from the perspective of history or from that of reality, lies in its ethical and moral theory. Confucius formulated a unique system with 'goodness' as the nuclear core confirmed by 'rites' and advocated the idea of 'guiding the people by moral force and keeping order among them by ritual'. Goodness as the highest moral standard in Confucianism has dual meanings: an intense concentration of Confucius's 'political thinking', representing Confucius's hope that the ruling class may 'rule by benevolence', and the high realm of Confucius's moral cultivation, showing his hope that people may be 'benevolent'. To practise 'goodness' lies in the loyal way: 'you yourself desire standing, then help others to get standing. You yourself want success, then help others to attain success', and in the tolerant way: 'never do to others what you would not like them to do to you' (the 'golden rule' of western philosophy). Confucius attached great importance to moral education and he considered that people showed little difference from one another when born and that only education differentiated individual from individual. Therefore, he recommended that moral education be used as the foundation of ruling a state and emphasized the notion of 'rescuing people by moral power'. Just as Professor Luo Guejie, a well-known Chinese ethicist pointed out, at the time when ancient Greek thinkers claimed openly that slaves were only tools that could speak, Confucius in China explicitly formulated the concept of loving people as 'the most fundamental and the only moral principle' (1). This is of great significance in the development of human civilization.

'Ritual', a category rich in connotations in Confucian culture, includes anything from rites to moral principles and from political systems to legal principles. But, in the commonest sense, 'ritual' mainly refers to the extensive system of moral principles corresponding to 'goodness'. The relation between 'goodness' and 'ritual' is that 'goodness' is the soul of 'ritual', 'Goodness' is the moral standard to be attained by 'ritual', and 'ritual' is the expression of 'goodness'. The former is subordinate to and serves the latter.

The ethical and moral theory of Confucianism stresses man's spiritual realm and holds that the moral demand is man's most pressing demand. Mencius regards morality as the biggest difference between men and animals and he ridiculed those who were well fed, well dressed and lived in splendid surroundings but lacked moral cultivation, as showing hardly any difference from animals $(5,6)$. Confucianists also emphasized the methods of moral education. Confucius himself stressed 'selfrestraint', 'introspection', 'self-respect' and 'selfblame'. Zeng-tse, the chief of another school of thought, said, 'I inspect myself three times daily'. Mencius also upheld cultivation of one's moral character. It can be seen that Confucian scholars consistently endorsed the enhancement of moral character by self-inspection and self-restraint.

Zhang Zhai (1020-1077 AD) succinctly summarized the goal of Confucianism: to set rules and laws for the state, to set morality for the people, to inherit the cultural achievements of ancient sages and to seek eternal peace under heaven. These features of Confucianism met fully the needs of feudal rulers. Therefore, Confucianism was reverenced as the nation's only orthodox school of thought in various dynasties from the time of Emperor Han Wudi (140-87 BC) and penetrated all walks of life in ancient society. Confucianism developed a series of deep-rooted concepts in the thought, consciousness and customs of people, becoming the mainstream culture and defining people's thoughts, words and acts, and playing an important role in China's history, unparalleled by any other school of culture (7). It was involved in the whole process of creating the culture of feudal society and defined the tone and pattern of feudal China's social thoughts and culture. The impacts of Confucian culture have to be considered if one wants to know ancient China and study modern China.

\section{Chinese medical ethical traditicn and its relation to medicine and Confucianism}

There are some legendary stories praising physicians for their morality before the time of recorded words. 
One of the most notable stories is about the ancient Emperor, Shennong, who tasted a hundred kinds of herbs and was poisoned 70 times one day. The story shows that in ancient times our ancestors were willing to sacrifice themselves in order to save lives and develop medicine. Records of ancient medical ethics can be dated back to the time prior to the formulation of Confucianism. In the Zhou Dynasty 3,000 years ago, the skills and the moral character of physicians were examined annually and physicians were treated differently, according to their examination results (8). After the establishment of Confucianism, its ethical and moral concepts exerted profound influences on medical workers of various dynasties and played a dominating role in the development of Chinese traditional medical ethics.

\section{Craft of saints}

First, there were some distinguished physicians who advocated medicine and opposed witchcraft. For instance, Hippocrates's contemporary, Bian Que ( 5 th BC), a famous physician in the Warring States Period (475-221 BC), formulated guidelines for practising medicine in which he proposed to trust in medicine rather than witchcraft. He saw as a realistic goal, the elimination of the harms of sorcery through the construction of medical ethics. Medical ethics were also emphasized in the famous traditional Chinese medical classic The Yellow Emperor's Canon of Internal Medicine (9), in which it is pointed out that medicine is the craft of saints, and a noble profession and that medical workers should have noble moral character. The book also enumerates five types of fault and four types of error in medical treatment and physicians are warned against these faults and errors. For example, physicians are required to practise medicine scientifically. It is also stressed that 'one who believes in ghosts or gods cannot be said to be benevolent' (8). For ancient physicians, advocating science and opposing superstition was one of the important aspects of medical moral character, which was highly appreciated by ancient physicians and in ancient medical writings.

In the following 1,000 years from $500 \mathrm{BC}$ to 500 $\mathrm{AD}$, serious inquiry was made into problems such as the purpose of medicine, style of work, and moral character cultivation. Many precious writings on medical ethics were handed down. Zhang Zhonging (circa 150-219 AD), a famous physician of the East Han Dynasty, who was regarded as a 'medical saint', said that his purpose in learning and practising medicine was to cure rulers and their relatives of illness, to relieve the common people of distress, and to promote health and prolong life (8). In his book, Treatises on Febrile Diseases, he harshly criticized irresponsible physicians by pointing out the harm and hazard of malpractice among physicians who did not diligently improve medical skills, who followed the beaten path, who practised medicine without care and who prescribed medicine rashly for $\stackrel{2}{\propto}$ patients. Benevolence, honesty and sagacity were $m$ also regarded by some as important aspects of $\overrightarrow{\bar{z}}$. physicians' moral cultivation. Dong Feng (3rd ? century AD), a famous physician in the period of $\Rightarrow$ Three Kingdoms, 'treated people without any $\stackrel{5}{9}$ charge. Five apricot trees were to be planted when $\bar{c}$ one was cured of a serious illness and one apricot $\frac{\bar{F}}{\bar{D}}$ tree was to be planted when one was cured of a $\frac{\bar{\sigma}}{\odot}$ minor disease. Several years later, a forest of $\stackrel{\mathbb{}}{\complement}$ 100,000 apricot trees appeared'. Each year, apricots $\$$ were exchanged for grains which were distributed to $\vec{\circ}$ the poverty-stricken. Over 20,000 people benefited from his generosity each year (10). The phrase $\vec{\omega}$ 'warm spring in the apricot wood' has since been used to praise the noble moral character of a physician (8). Yang Quan, a physician of the Jin Dynasty is stressed that a physician must be benevolent, $\overrightarrow{\vec{A}}$ sensible and honest and must have a noble character i as well as excellent skills.

The Tang Dynasty (618-907 AD) was one of the $\frac{\text { ? }}{3}$ periods of great prosperity in ancient China. The time was ripe for summarizing the medical ethical $\stackrel{D}{\longrightarrow}$ tradition in the context of political, economical and cultural development. Tsun Simiao (581-682 AD), $\stackrel{\text { ? }}{+}$ a famous physician and pharmacist, was an import- $\overrightarrow{0}$ ant pioneer in the field of medical ethics in ancient of China. One of the articles in his important book Golden Essential Recipes, is the earliest and moyt famous monograph on medical ethics. He annotate्gl the title of the book by saying 'human life is more precious and valuable than a thousand gold pieces $\frac{\mathrm{D}}{\mathrm{O}}$ and one good recipe prescribed can be life-saving; therefore, the name of Golden Essential Recipes is chosen'. The medical ethical thinking of Tsun Simiao was highly appreciated by both Chinese and foreign scholars. A Japanese professor once remarked, 'Today we talk about respecting human life. Thirteen hundred years ago, Tsun Simiao in $\frac{\mathbb{}}{\sigma}$ ancient China explicitly pointed out the truth and 3 . wrote about it' (11). The only copy of the North 8 Song Dynasty (960-1127) version of the Golden 3 Essential Recipes is carefully preserved in Japan and is 0 regarded as 'a national treasure' by the Japanese government. In his famous monograph on medical ethics, Tsun Simiao set the norm for scholarly attitudes, style of medical practice, character cultiva- $\sigma$ tion, deportment and academic ethics. It can be seen $N$ from Tsun Simiao's systematic summarization, and $\mathbb{W}^{2}$ from his contribution, that Chinese traditional 0 medical ethics was at that time entering a period of maturity and stability.

\section{Principles of medical ethics}

During the Ming Dynasty (1368-1644), efforts were made to set up principles of medical ethics. $\mathrm{Li} \overleftrightarrow{\mathrm{Q}}$ Shizhen (1518-1593) can be said to have provided $\cong$ the model of integrity in medical and medicinal studies with the re-writing of his book, Compendium 
of Materia Medica. He showed his respect for the work of others by giving references to the original literature. Gong Jingxian in the 16th and 17th century enumerated 'ten tenets for physicians and ten tenets for patients' so as to co-ordinate the relationship between physicians and patients. His contemporary, Chen Shigong (1555-1636) put forward Five Commandments and Ten Tenets for Physicians (12), which is similar to present-day ethical principles for physicians.

In the Ming and Song Dynasties, some physicians were also critics of medical ethics. They criticised harmful tendencies in medical practice, thus demonstrating that medical ethical criticism has long been present in the construction of Chinese traditional medical ethics.

Throughout China's long history, a rather highly developed system of Chinese traditional medical ethics has emerged with well-defined basic contents. These lay down that all medical workers should abide by the following six tenets.

\section{Value of human life}

First, they should appreciate the value of life and rescue the dying and heal the wounded by all means available to them. A lofty concept of the value of human life was established among ancient physicians, as reflected in Tsun Simiao's remark that 'human life is more precious and valuable than a thousand gold pieces'. Tsun Simiao was also determined to relieve all human beings from suffering, showing his sense of responsibility in rescuing the dying and healing the wounded. Gong Tingxian of the Ming Dynasty also pointed out that 'medicine is for living people' and that 'in a physician's hand lies the life or death of a patient'.

Second, they should care for patients' suffering and practise medicine with honesty. Tsun Simiao maintained that a physician should bear the suffering of patients in mind, not his own material interests. In Five Commandments and Ten Tenets for Physicians, Chen Shigong also asked physicians to practise medicine with integrity: they should not replace precious herbal materials provided by the family of the patients with inferior ones, nor charge the poor, and wandering monks. And what is more, he urged physicians to give as much financial support as possible to poverty-stricken patients, for he believed that no medicine could cure any person with an empty stomach. He also suggested that physicians should not be extravagant but should live simply. He held that it was much better to save money than to charge more fees.

Third, they should diligently improve medical skills and oppose careless styles of working. The Yellow Emperor's Canon of Internal Medicine pointed out that physicians 'should be knowledgeable about heaven, earth and man' in order to be qualified doctors. Famous ancient physicians such as Zhang
Zhongjing, Tsun Simiao and $\mathrm{Li}$ Shizhen were all diligent in studying medicine and they were not afraid of difficulty and hardships. Tsun believed that a physician should concentrate thoroughly and be most careful, and absolutely accurate, when diagnosing a disease.

Fourth, they should act with decorum, decency and politeness. The Yellow Emperor's Canon of Internal Medicine requires physicians to 'ask about the customs when entering a foreign state, ask about things forbidden when visiting a household and ask about manners when practising medicine'. This shows that the good tradition of respecting customs and practising medicine with integrity has been stressed since ancient times. In Rules and Regulations for Practising Medicine, Li Yan of the Ming Dynasty wrote: 'when diagnosing a woman, an immediate relative of hers should be invited to question the woman about signs, the tongue and dietary habits first', and 'more respect should be paid and more caution should be given when one gives medical treatment to a widow or a maid'. In Five Commandments and Ten Tenets for Physicians, Chen Shigong pointed out that a prostitute who came to see a doctor should be treated as if she was a good lady and the physician should not take liberties with even such a woman. These moral requirements showed the tradition of respect for patients, especially for woman patients, by physicians in ancient China.

Fifth, they should acknowledge that all patients are equal before a physician. This concept was significant and progressive in a hierarchical, feudal society. In The Integrity of a Respected Physician, Tsun Simiao stressed that patients coming for treatment, whether rich or poor, old or young, beautiful or ugly, close or distant and Chinese or foreign, should be treated the same as an immediate relative or a good friend. Gong Tingxian also criticized doctors who only liked to give treatment to the rich and neglected the poor, for acting contrary to the purpose of medicine.

Sixth, they should respect other people's achievements and abide by academic ethics. Tsun Simiao said a physician should not be conceited and arrogant. In the Compendium of Materia Medica by $\mathrm{Li}$ Shizhen, The Medical Secrets of an Official by Wang Tao, and Classified Materia Medica by Tang Shenwei, good examples to fellow physicians were set out. In Five Commandments and Ten Tenets for Physicians, Chen Shigong also warned against arrogance and slandering and endorsed humbleness, caution, respect and tolerance. As it was customary in feudal China that people of the same occupation despised one another, these moral requirements showed the great courage of physicians in pursuing medical ethics.

\section{Unique structure}

Confucianism occupied a longstanding dominant position in ancient China and, moreover, 'from its 
goal, function and structure, it can be said to be a school centred around ethics and morality' (1). It certainly exerted immense and profound influences on the development of medical ethics in ancient China.

Its influences are mainly and fundamentally positive.

First, the school of Confucianism established a unique structure of moral principles with goodness as the nuclear core confirmed by rites. This system did not only exert immense influences on Chinese culture, which was then in the process of civilization, but also served as the keynote of Chinese traditional medical ethics. In ancient China, medicine was called 'the craft of benevolence' or 'the craft of saints', representing the hope that physicians would act by the Confucian concept of 'benevolence' and practise medicine by the teachings of Confucian saints. Various rules and regulations of medical ethics contained instructions such as: ' $\mathrm{Be}$ benevolent and Confucian' and 'First know the logic of Confucianism and then the logic of medicine'. These show that physicians regarded it as honourable to know and follow Confucianism. In The Analects of Confucius's Fellow Villagers, it was recorded that Confucius's stable was burned down. Upon learning of the event, Confucius first asked if anyone was hurt rather than asking about the horses. This story has progressive significance in a society where a horse was worth five slaves. Humanitarian ethical thinking as embodied in the theory of Confucianism exerted a direct effect on the concept of the value of human life and human dignity. Physicians of various dynasties all stressed that physicians must be benevolent and that the purpose of practising medicine was to rescue the dying and to relieve the distressed. These principles have become guidelines for the practice of medicine. In practice, physicians of various dynasties all regarded it as a lofty goal to be 'a respected physician of the multitude' and to 'relieve all human beings from suffering'. It can be said that in ancient China, only physicians had the highest and noblest professional morality and there were many folk stories praising the deeds and morality of physicians. All this is thanks to the influence of Confucian humanitarian ethical thinking on traditional medical ethics.

Traditional medical ethics concerning the concepts of justice and benefit were also profoundly influenced by Confucian thinking. The Confucian concept of 'justice before benefit' requires doctors to give justice priority and to regard honesty as a duty. To give justice priority means to regard saving and treating others as one's destined duty. As Chen Shigong pointed out: 'man receives orders from heaven and should not act otherwise'. Secondly, physicians should have a self-sacrificial spirit. Tsun Simiao said in effect that one should devote oneself to the treatment of patients and should not shun difficulties and hardships and should not consider one's own loss and gain. Moreover, the justice and $\frac{1}{2}$ benefit' concept of Confucianism instructed doctors $\varrho$ to be honest and pure and not to seek material gain. $\vec{F}$. Under the influence of such thinking, many doctors regarded practising medicine as a charitable activity and worked without seeking fame or benefit. The $\stackrel{\vec{T}}{+}$ low price of herbal medicine and acupuncture for $\bar{C}$ relieving pain demonstrated a humanitarian concern $\frac{}{\bar{F}}$ aimed at ensuring that the common people had $\frac{\bar{\omega}}{\frac{1}{\sigma}}$ access to medical resources.

Maintaining a proper relation between physicians and patients has been consistently emphasized in $\overrightarrow{0}$ Chinese traditional medical ethics, which was deeply influenced by the Confucian concept that 'man is $\vec{\omega}$ born good'. In classical Confucian writings, $\stackrel{\text { ? }}{\rightarrow}$ Confucius outlined a series of principles and norms $\overrightarrow{\overline{0}}$ for showing respect for, and sympathy to, people, i based on an appreciation of human values and human dignity. For example, 'Never do to others is what you would not like them to do to you', and $\omega_{0}^{\omega}$ 'People within the four seas are all brothers', and 'A 을 noble man helps others to carry out only their good wishes, not their evil ones'. These philosophical $\gg$ teachings penetrated the hearts of everyone inco ancient China. These teachings require that $\stackrel{5}{\rightarrow}$ physicians show respect for patients and that $\vec{\theta}$ patients should choose a sensible physician and $\mathscr{C}^{\circ}$ comply with the physician by taking the medicin prescribed. Patients are also asked to receive treas. ment as early as possible and to believe in medicire rather than witchcraft. A good physician-patient relation will be formed with respect and care for patients by doctors and reliance on, and compliance with, doctors by patients. Tsun Simiao asked doctors to regard the sufferings of patients as their own afflictions and to treat patients with profound sympathy.

These attitudes of 'thinking about patients and thinking for patients' are a further application and development of Confucianism in medical ethics and provide an emotional basis for establishing satisfactory physician-patient relationships.

\section{Moral education}

The emphasis placed by Confucianists on moral education and moral cultivation also has direct relevance $\tilde{N}$ for the promotion of traditional medical ethics and $N$ the enhancement of physicians' moral cultivation. N Many writings were available on ancient medical $\omega$ ethics which held that by learning Confucianism one knows the truth and by knowing the truth one becomes a good physician. In other words, $\stackrel{\mathbb{S}}{+}$ Confucianism teaches people to promote moral character by self-cultivation, which is also beneficial ${ }^{-}$ to the construction of medical ethics. In ancient $\stackrel{\overrightarrow{\mathrm{D}}}{\mathrm{D}}$ China, there were many examples of individuals who $\frac{?}{\mathbb{P}}$ were both famous physicians and famous $\varrho$ Confucianists. The Integrity of Respected Physicians by Tsun Simiao was not only regarded as a classic on 
medical ethics but also as representative of Confucian writing on ethics. Famous physicians in ancient times usually had great virtue. They taught their students how to be upright men before instructing them to become physicians; this almost became a set pattern in the history of the development of medicine in China. All this demonstrates that the moral pursuit of medicine and Confucianism is consistent and that this consistency is deeply rooted in the Confucian tradition, which emphasizes moral cultivation and stresses spiritual pursuit.

Though Confucian culture has exerted positive influences on the development of Chinese traditional medical ethics, it also has its historical and class limitations, which adversely influenced traditional medical ethics. For example, in the long process of history, Confucian culture intensified the concepts of hierarchy, loyalty and filial obedience. These Confucian concepts caused some unscientific and unreasonable norms and beliefs to spring up in traditional medical ethics. For example, Confucianism over-emphasized the value of human life and was overcautious about contact with the other sex. The Book of Filial Obedience said that each and every part of the human body is contributed by the father and mother and no damage or injury should be done to it. As a consequence, it was held that surgery and autopsy were immoral. Moreover, the superior position of men over women and the concept that private contact between men and women was deemed improper were strengthened by the development of Confucianism. Some medical ethical regulations stipulated that a woman without company should not be treated and that a physician treat his women patients over a curtain. These rules were neither advantageous to women nor convenient for physicians. Indiscriminate pursuit of 'goodness' can only lead to actual 'evil' and as a consequence, the norms of medical ethics may be unscientific (13). Furthermore, some Confucian scholars took the concept of 'valuing righteousness and despising benefit' to an extreme. Such Confucian sayings were often quoted as: 'Great men pursue moral principles rather than food ... and worry about moral principles rather than poverty', and 'Great men pursue what is right; petty men pursue what is profitable'. Righteousness and benefit, and moral value and material interest were set against each other. As a result, goals were often unreachable and norms were often contradictory in medical ethics. Finally, the Confucian tradition of moral education and spiritual pursuit was developed into an idealist philosophy during the Song and Ming Dynasties which reduced the practicality and applicability of traditional medical ethics.

\section{The role of Confucian culture in the construction of modern medical ethics}

From the perspective of history, Confucianism is neither a static system nor a meaningless antique in the contemporary world. It is an open system that moves forward with social development. In Singapore, Confucian moral education is systematically being carried out under the leadership of the government. Some Japanese enterprises also appreciate the role of Confucianism in improving business operations. In the Selected Works of Mao Zedong, Confucian sayings were quoted over 50 times. These examples clearly demonstrate that correct evaluation of the position of Confucian culture in our history, and separation of the essence from the dross in Confucianism, are of significance in the construction of spiritual civilization as well as in that of medical ethics.

At present, with the rapid development of modern science and technology, new methods are created and new wonders are wrought in medicine, but these also bring about new contradictions in medical ethics. Are our efforts to enhance the quality of life by modern reproductive techniques worthwhile? Is euthanasia for patients with terminal illness appropriate? Do the new techniques such as artificial fertilization, test tube babies, organ transplantation, behaviour control and genetic engineering pose challenges to human dignity? These problems have posed dilemmas for many concepts of traditional ethics. With the achievements in biological engineering, man is once again put in a perplexing situation (13). Many traditional ethical concepts are being reviewed and many new notions have come into being. Jean Davies, Chair of the World Active Voluntary Euthanasia Association, remarked during her visit to our university that: 'Man's thinking is ever changing. My grandmother's contemporaries talked about money; my mother's talked about sex and ours are now beginning to talk about death'. How to keep continuity by inheriting and perpetuating the essence of traditional medical ethics and how to renew medical ethics is a very serious question. Confucian culture, which has played an immensely important role in the formation and development of traditional medical ethics, also needs objective appraisal and amendment so that Chinese ancient culture may play a proper role in the construction of modern medical ethics. Four things need to be done.

1. The Confucian tradition which emphasizes moral education and moral cultivation should be modernized and promulgated so that people may be strengthened by the concept that the construction of spiritual civilization should be highly regarded in a materially developed civilization. As part of the construction and formulation of medical ethics, laws and regulations should be drawn up and noble moral character as shown by physicians in practising medicine should be endorsed, while misconduct should be disciplined or punished. Medical ethical education and practice and medical ethical evaluation should be integrated into the framework of medical education and medical practice. 
2. The Confucian concepts of benevolence, righteousness and benefit, human value and filial obedience, which show historical limitations, need to be reconstructed. The essence of these concepts which will promote the development of medicine and help co-ordinate interpersonal relations should be kept, so that Confucianism can serve medicine and the ancient can serve the present. In the process, we should note the differences or contradictions in many Confucian concepts and make suitable explanations. For example, according to Confucian culture, active euthanasia is not benevolent and passive euthanasia is not good. If we look to the future and renew Confucian concepts about the value of human life and benevolence, it will be helpful in renewing people's ideas and thinking.

3. Such Confucian concepts as nobles being superior to the common people and men superior to women, should be completely discarded so as to adapt to social progress and development in medicine. In some remoter parts of China, negative ideas about birth and mysterious notions about sexual medicine are related to outdated notions in Confucian culture.

4. We should learn from fellow scholars in foreign countries. We ought to introduce new medical ethical theories into China. We should also attach importance to: the enhancement of the quality of life; how best to safeguard the environment, and the need to carry out investigations into the difficult medical ethical problems arising from high technology. Moreover, the medical legal system, the supervising system and punitive measures should be in keeping with international norms. This will be a great help in the construction of Chinese modern medical ethics as well as in the reforming of the health system.

Guo Zhaojiang is Professor in the Political Department at The Fourth Military Medical University, Xian in The Peoples' Republic of China.

\section{References and notes}

(1) Luo, G. A study on Confucian ethical thinking. Literature and history 1988: Jun.

(2) Luo, G. Annotation of ethical terms. Beijing: People's Publishing House, 1986.

(3) Zhang, C. Historical evolution of Confucianism and its functions. Fournal of philosophy and sociology 1988: Jan.

(4) Wen, K. On the ethical thinking of Confucian of humanism. Fournal of Tianjin University 1987: Feb.

(5) Zhang, G. Pros and cons of theories on benevolence and benefit of Confucianism, Mohism, Taoism and Legalism in early Qin dynasty. Xinhua reader's digest 1992: Jan.

(6) Qu, Y. On Mencian viewpoints of value. Xinhua reader's digest 1992: Sept.

(7) Zhong, Z. Confucianism in substitution for religion. Xinhua reader's digest 1992: May.

(8) Encyclopedia of Chinese medicine: history of medicine. Shanghai: Shanghai Science and Technology Publishing House, 1987.

(9) According to the Encyclopaedia of Chinese medicine: history of medicine (see reference (8): 167), an American named I Veith got his doctorate degree by virtue of having translated The yellow emperor's canon of internal medicine (1949). Scholarly works like World outlook and principles concerning astronomy, universe, physics and phi losophy of the Chinese by a British man named Alfred Forke (1925), Chinese medicine by an American named William Morse (1934), and Plain questions - basics Chinese medicine, by another American named $M^{T}$ Dawson, all refer to the contents of this great book.

(10) See reference (8): 88.

(11) Sun, P. Master pharmacist Tsun Simiao. Shaanxi People's Publishing House, 1983.

(12) Guo, Z. New edition of medical ethics. Lanzhou: Lanzhou University Press, 1988.

(13) Guo, Z, et al. An outline of medical ethics. Shaanxi Science and Technology Publishing House, 1991. 